\title{
Occupation, Hours Worked, Caregiving, and Leisure Time Physical Activity
}

\author{
S. L. Kuiack, H. M. Irving, and G. E. Faulkner
}

\begin{abstract}
This study hypothesized that occupational variation in leisure-time physical activity or exercise may be due to differential caregiving demands on blue versus white-collar female employees. Data from the 2000 Kings County Genuine Progress Indicators Survey (1,900 respondents aged 15 years and older) were analyzed. Results indicate that variation in LTPA is accounted for by caregiving to dependent children at home and health status and not by occupational status. Implications for health promotion strategies are discussed.

Stephanie L. Kuiack, Ph.D. is Assistant Professor, Department of Family Studies, Brescia University College, London, Ontario, Canada, N6G1H2. Electronic mail may be sent via the Internet to skuiack@uwo.ca.
\end{abstract}

Key Words: Caregiving, leisure-time physical activity, occupational status

Many studies have found that caregivers tend to neglect their own health care needs (Acton, 2001; Castro, King, Bacak, Housemann, Gardiner, \& Brownson, 2003; Janevic \& Connell, 2001). This neglect comes in many forms, but one of considerable interest is neglect of leisure time physical activity (LTPA) and exercise. Caregivers who do not exercise regularly miss out on many well documented benefits of regular physical exercise 
including improved overall health, decreases in blood pressure, improvements in lipid profile, weight control, helps in diabetes control, reduction of stress, promotion of relaxation, as well as a number of positive psychological effects.

It is essential that caregivers make time to provide care for themselves, including sufficient LTPA. The entire experience of caregiving can be undermined when the caregiver does not take sufficient care of themselves. Compromised caregiver health has been linked to potentially harmful behaviors by caregivers, including screaming, yelling, insulting, swearing, threatening to send to a nursing home and withholding food (Beach, Schulz, Williamson, Miller, Weiner, \& Lance, 2005). Karlin (2004) concluded that lack of LTPA or exercise during care-giving periods predicted higher levels of caregiver burden. Alternatively, Rabinowitz, Cardenas, Mausback, Gray and Ambler (2003) found that overall burden was predictive of poor health behaviors for caregivers. Exercise programs directed to caregivers have shown success in reducing sense of caregiver burden (Boise, Congleton \& Schmall, 2000; Castro, Wilcox, O’Sullivan, Baumann, \& King, 2002).

The exploration of the barriers to regular LTPA for caregivers has revealed regional variation (Wilcox, Castro, King, Housemann, \& Brownson, 2006) in that rural caregivers are more sedentary than their urban counterparts. Rural women cited caregiving duties as their top barrier to LTPA as compared to lack of time for the urban women. Variation has also been reported due to ethnicity, age, and education level (King, Castro, Wilcox, Eyler, Sallis, \& Brownson, 2006). For all ethnic subgroups, care-giving duties ranked among the top four most frequently reported barriers to LTPA. The exploration of why some caregivers cannot engage in regular LTPA has incorporated the fact that caregiving and LTPA may be mediated by other factors. Caregivers often have multiple competing demands for their time including providing care to their own children as well as employment (Burton \& Turrell, 2000). 
Occupational Status and LTPA

Occupational status has an important bearing on LTPA pursuits. Studies have demonstrated that blue collar employees report lower levels of LTPA (Niknian, Linnan, Lasater, \& Carleton, 1991; Oldridge, 1992). As a direct result, demographic studies have shown that blue collar employees experience higher mortality and morbidity rates (Bennett, 1996). A study by Burton and Turrell (2000) investigated the relationship between occupation, hours worked and LTPA. The authors reported that individuals in blue-collar occupations were approximately 50\% more likely to be classified as insufficiently active. However, this occupation variability in leisure-time physical activity was not explained by hours worked. The authors suggested that identification of factors contributing to occupational variability in leisure time physical activity may add to our understanding of why population subgroups differ in their health risk profiles. One such factor proposed was that individuals may be constrained by other time demands, such as caregiving commitments.

Occupational Status, Caregiving, and LTPA

Although the literature presents a compelling case that caregiving interferes with LTPA and that individuals employed in particular occupation categories exercise more than others, there has yet to be an examination of the influence of both occupation and caregiving responsibility on LTPA. The objective of the present study was to examine occupation, hours worked, caregiving demands and LTPA in a large rural sample. We hypothesized that blue collar caregivers would engage in less LTPA than white-collar or professional-occupation caregivers. 


\section{Methods}

\section{Study Design}

Data for this study were derived from the 2000 Kings County GPI Survey, a random sample of 1,900 respondents aged 15 years and older. The 2000 Kings County GPI Survey was conducted by GPI Atlantic, a non-profit research group. The survey collected information on demographics, leisure-time physical activity, labour force participation, community values, population health, civic and voluntary work, care-giving and support networks, employment and income, time use, and other essential variables of the Genuine Progress Index (GPI). Respondents provided informed consent and completed selfadministered questionnaires in their homes. The response rate of the survey was $70 \%$.The 2000 Kings County GPI Survey received approval from both the Dalhousie and Acadia University's Research Ethics Boards.

\section{Population}

For the current study, the sample was restricted to the 521 women aged 18 to 64 who were in the paid labor force during the week preceding the survey. The sample size was further reduced to 490 cases $(94.2 \%)$ due to listwise deletion of missing data for measures included in this study.

\section{Dependent Variable}

Physical activity. Respondents were asked about the frequency of participation in sports or other physical exercise (i.e., such as swimming, bicycling, jogging, exercising, walking for exercise, active yard work or gardening, dancing, basketball, and hockey) during their leisure time in the past 3 months. Women were considered insufficiently active (coded 1) if they had not 
participated in any of these leisure-time physical activity on at least 5 days of the week.

\section{Independent Variables}

Occupation. Respondents who were employed in the paid labour market during the week preceding the survey were asked to indicate their occupation based on a list of ten categories in addition to "other." The categories included, for example, management, health, trades, transportation, and equipment operator. They were also asked to report the job title of their main job. Following Burton and Turrell (2000), these data were used to derive three occupational groups. Professionals included managers and administrators, professionals, and paraprofessionals. Whitecollar workers included clerks, salespersons, and personal service workers. Blue-collar workers included tradespersons, plant and machine operators and drivers, and laborers and related workers. Occupation was represented in the logistic regression analyses with 2 dummy variables. Professional workers were the reference category.

Hours working at a paid job. Time spent working at a paid job was measured by a dichotomous variable with 1 representing women who worked less than 30 hours per

week, and 0 representing those who worked 30 or more hours per week.

Hours spent providing unpaid care. Respondents were asked to indicate whether they provided unpaid care for an elderly relative or friend, or an adult child, who lived either with them or outside their home. If they reported being caregivers, they were asked to indicate the number of hours (including travel time) they spent providing care. These two variables were used to derive a binary measure that compared women who provided at least one hour of care-giving per week (coded 1) with those who did not (coded 0). 
Presence of dependent children. Women who reported having dependent child/children in the household (coded 1) were compared with those who did not (coded 0 ).

Weight status. Participants' self-reported height and weight were used to compute BMI, calculated as weight in kilograms divided by the square of height in meters. According to the WHO (2003) definition, women with a BMI value of 25.0 or greater were classified as being overweight/obese (coded 1) and those with a BMI value of less than 25.0 were classified as being of healthy weight (coded 0 ).

Smoking status. A single question concerning smoking behaviour requested that respondents indicate the frequency of smoking (i.e., daily, weekly, monthly, not at all). This measure was recoded into a binary variable with 1 representing non-smokers and 0 representing smokers.

Perceived physical health. Respondents were asked to rate their health on a five-point Likert scale ranging from excellent to poor. This perceived health measure has been validated as a reliable indicator of health problems, health care utilization, and mortality (D’Arcy, 1998; Idler \& Benyamini, 1997). This measure was dichotomized, with 1 representing excellent, very good or good health (good health) and 0 representing a fair or poor health (poor health).

Demographic control variables. Demographic control variables included age and marital status. Age was coded into 5 categories: 18-24; 25-34; 35-44; $45-54$ and 55-64 and was represented in the logistic regression analyses with 4 dummy variables. Women aged 18-24 were the reference category. Marital status was coded 1 for women who were married or living together as married; 0 for non-married.

\footnotetext{
Analysis

We used logistic regression analyses to examine the associations between physical
} 
activities, occupational status, hours worked and hours spent providing unpaid care for an elderly relative or friend, or an adult child. These associations were adjusted for age and marital status. We adjusted for these variables because previous studies have shown that they are associated with physical activity, occupation, and care-giving. All statistical analyses were conducted using STATA 8.2 (StataCorp, 2003).

\section{Results}

Table 1 presents the characteristics of the study sample. Of the 490 women, the majority (37.4\%) were between 35 and 44 years of age. Most women were married or in common law relationships $(78.2 \%)$, and $36.9 \%$ had dependent children living in their households. The majority of women perceived their physical health as good $(89.8 \%)$, were non-smokers $(74.5 \%)$, and slightly fewer than half $(46.9 \%)$ were of healthy weight (BMI of < 25). Most women (68.2\%) participated in insufficient physical activity (i.e., less than five days per week) and worked 30 or more hours per week $(65.5 \%)$. Only $10 \%$ of women provided at least one hour per week of unpaid care for an elderly relative or friend, or an adult child, who lived either with them or outside their home. Almost half of the women (49.8\%) were in white collar occupations, followed by $41.4 \%$ and $8.8 \%$ in professional and blue collar occupations, respectively.

Table 2 reports the results of the logistic regression analyses that examined the associations between physical activity, occupational status, hours worked and hours spent providing unpaid care for an elderly relative or friend, or an adult child. Results in Model 1 indicate that, controlling for age and marital status, occupational status was significantly associated with participation in physical activity. More specifically, the odds of participation in insufficient physical activity (less than 5 times per week) were greater among women in blue collar occupations (OR $=2.43[95 \% \mathrm{CI}=1.01-5.84]$ ), than among women in professional occupations. As shown in Model 2, the association between 
physical activity and occupational status remained significant with adjustment for hours spent working at a job. Model 3 shows that time spend providing unpaid care for an elderly relative or friend, or an adult child also did not significantly change the relationship between physical activity and occupational status.

Results in Model 4 illustrate that when the additional independent variables were added to the model, the association of occupational status with physical activity became non-significant. Only the presence of dependent children in the household and perceived health was significantly associated with participation in physical activity. Women who resided in households with dependent children were more likely to be insufficiently active $(\mathrm{OR}=1.68[95 \% \mathrm{CI}=1.03-2.73])$ than their counterparts who resided in households without dependent children. In addition, perceived heath was significant, with lower odds of participation in insufficient physical activity among women who perceived their health as good $(\mathrm{OR}=0.38$ [95\% CI $=0.17-0.84])$ compared with women who perceived their health as poor. These findings suggest that the presence of dependent children in the household and perceived health status are two important factors that help to explain the association between occupational status and participation in regular physical activity among women.

\section{Discussion}

The objective of this study was to examine occupation, hours worked, caregiving demands and LTPA. In keeping with previous research findings (Burton \& Turrell, 2000), participation in insufficient physical activity (less than 5 times per week) was greater among women in blue collar occupations than among women in professional occupations. Contrary to our hypothesis, time spent providing unpaid care for an elderly relative or friend, or an adult child did not significantly change the relationship between occupational status and physical activity. Only the presence of dependent children in the household and perceived health were significantly associated with participation in LTPA. 
These results suggest that care-giving to dependent children interferes more with the pursuit of LTPA than caregiving to others, regardless of occupational status. It may be that care-giving needs to be understood in terms of the care receiver. Nearly $37 \%$ of the sample had dependent children at home, while only $10 \%$ provided care to an elderly relative, friend, or an adult child. This finding must be considered in the context of how caregiving was measured. Those women who were coded as caregivers indicated they provided one or more hours of care per week versus those who did not. Perhaps a more sensitive measure of time spent on care-giving would reveal the critical point in terms of time where caregiving responsibilities interfere with LTPA.

It is important to note that the majority of the women in this sample worked more than 30 hours per week at paid employment. Many caregivers to the elderly or infirm either reduce the number of hours they work or quit work to care for the patient (Covinsky, Eng Lui, Sands, Sehgal, Walter, Wieland et al., 2001). It may be reasonable to surmise that if caregiving does not interfere with paid employment, or at least warrant a reduction in work hours, then it is not so demanding as to rob time away from LTPA pursuits. Alternatively, caregivers may maintain their work hours but engage in care-giving rather than pursue LTPA or exercise. Future studies should specifically ask caregivers how they spend their time versus how they would like to spend their time to begin to appreciate if caregiving per se is replacing activities such as LTPA or exercise.

Interestingly, perceived heath was a significant motivator for LTPA. Women who perceive their health to be good were more likely to engage in LTPA than those who did not. Regarding one's health to be compromised may act as a barrier to LTPA due to fatigue. One may choose to avoid LTPA or exercise as a caution to not aggravate an existing condition. Our sample was clustered into two groups; those reporting good health versus those reporting poor health. Perhaps a greater understanding of the conditions that warrant a rating of fair or poor health may provide a better picture of why LTPA is avoided. However, our measurement of physical 
activity included activities such as swimming, bicycling, walking for exercise, and gardening which may be engaged in despite ailments which lead to a rating of fair or poor health.

Burton and Turrell (2000) demonstrated that time spent at work does not explain variation in occupational status and LTPA. This present study has demonstrated that occupational variability in LTPA also cannot be explained by the addition of caregiving responsibility to the elderly or infirm for women. Motherhood or the care of dependent children in the home does have an important bearing on LTPA, as does perception of poor health status. Methodologies must be developed to examine the reason why blue collar caregivers are engaging in less LTPA than their counterparts. If it is not because they are busier with work or caregiving, we must continue to explore this issue in order to close the gap in health status between the occupational groups. In the meantime, health promotion strategies to increase the rate of participation in LTPA or exercise for women must take into consideration the competing demands on their time. Awareness raising campaigns to encourage women to exercise may need to directly address perceived obstacles to LTPA including lack of time due to motherhood or health status in order to reduce the variation in LTPA pursuits recognized between occupational status groups.

\section{References}

Acton, G. (2001). Health-promoting self-care in family caregivers of adults with cognitive impairment. The Gerontologist, 41(Spl.1), 99.

Beach, S. R., Schulz, R., Williamson, G. M., Miller, L. S., Weiner, M. F., \& Lance, C. E. (2005). Risk factors for potentially harmful informal caregiver behaviour. Journal of American Geriatric Society, 53(2), 255-261. 
Boise, L., Congleton, L., \& Schmall, V. (2000). Applying selfefficacy to caregiver education: The powerful tools for caregiving program. The Gerontologist, 40 (Spl. I), 244.

Burton, N. W, \& Turrell, G. (2000). Occupation, hours worked, and leisure-time physical activity. Preventive Medicine, 31, 673-81.

Castro, C., King, A., Bacak, S., Housemann, R., Gardiner, K., \& Brownson, R. (2003). Rural caregivers and health behaviors: Results from an epidemiological survey. The Gerontologist, 43 (Spl. 1), 48.

Castro, C. M., Wilcox, S., O’Sullivan, P., Baumann, K., \& King, A. C. (2006). An exercise program for women who are caring for relatives with dementia. Psychosomatic Medicine, 64(3), 458-468.

Covinsky, K. E., Eng, C., Lui, L., Sands, L. P., Sehgal, A R., Walter, L. C., Wieland, D., Eleazer, G. P., \& Yaffe, K. (2001). Reduced employment in caregivers of frail elders: Impact of ethnicity, patient clinical characteristics, and caregiver characteristics. Journal of Gerontology: Series A: Biological Sciences and Medical Sciences, 56, M707-M713.

D'Arcy, C. (1998). Social distribution of health among Canadians. In D. Coburn, C. D'Arcy \& G. M. Torrance (Eds.), Health and Canadian society: Sociological perspectives (3rd ed.) (pp. 73-101). Toronto, ON: University of Toronto Press.

Idler, E. L., \& Benyamini, Y. (1997). Self-rated health and mortality: A review of twenty-seven community studies. Journal of Health and Social Behavior, 38, 21-37. 
Eyler, A. A., Baker, E., Cromer, L., King, A. C., Brownson, R. C., \& Donatelle, R. J. (1998). Physical activity and minority women: A qualitative study. Health Education Behavior, 25(5), 640-652.

Janevic, M. R., \& Connell, C. M. (2001). Motivators and barriers to exercise among female spouse caregivers of people with dementia. The Gerontologist, 41 (Spl. 1), 39.

Karlin, N. (2004). An analysis of religiosity and exercise as predictors of support group attendance and caregiver burden while caring for a family member with Alzheimer's Disease. Journal of Mental Health and Aging, 10(2), 99-106.

King, A. C., Castro, C., Wilcox, S., Eyler, A. A., Sallis, J. F., \& Brownson, R. C. (2000). Personal and environmental factors associated with physical inactivity among different racialethnic groups of U.S. middle-aged and older-aged women. Health Psychology, 19(4), 354-364.

Rabinowitz, Y., Cardenas, Y., Mausbach, B., Gray, H., \& Ambler, C. (2003). Predictors of health behaviors of Alzheimer's demential patients: Ethnicity, kinship status and coping styles. The Gerontologist, 43(Spl. I), 332.

StataCorp. (2003). Stata Statistical Software: Release 8.0. College Station, TX: Stata Corporation.

Wilcox, S., Castro, C., King, A. C., Housemann, R., \& Brownson, R. C. (2000). Determinants of leisure time physical activity in rural compared with urban older and ethnically diverse women in the United States. Journal of Epidemiology and Community Health, 54(9), 667-672.

WHO. (2003). Overweight and obesity. Geneva: World Health Organization. 
Table 1: Characteristics of the Study Sample $(n=490)$.

\begin{tabular}{|l|l|l|}
\hline & N & Percent \\
\hline Age & & \\
\hline 18-24 years & 27 & 5.5 \\
\hline 25-34 years & 74 & 15.1 \\
\hline 35-44 years & 183 & 37.4 \\
\hline 45-54 years & 152 & 31.0 \\
\hline 55-64 years & 54 & 11.0 \\
\hline Marital Status & & \\
\hline Not married & 107 & 21.8 \\
\hline Married/Common-law & 383 & 78.2 \\
\hline Weight Status & & \\
\hline Healthy weight (BMI<25) & 230 & 46.9 \\
\hline Overweight/obese (BMI>25) & 260 & 53.1 \\
\hline Perceived Physical Health & & \\
\hline Poor health (fair, poor) & 50 & 10.2 \\
\hline $\begin{array}{l}\text { Good health (excellent, very good, } \\
\text { good) }\end{array}$ & 440 & 89.8 \\
\hline Smoking Status & & \\
\hline Current smoker & 125 & 25.5 \\
\hline Non-smoker & 365 & 74.5 \\
\hline $\begin{array}{l}\text { Presence of Dependent Children }(<\mathbf{1 8 y r}) \\
\text { in the Home }\end{array}$ & & \\
\hline No dependent child(ren) in the home & 309 & 63.1 \\
\hline Dependent child(ren) in the home & 181 & 36.9 \\
\hline $\begin{array}{l}\text { Frequency of Participation in Physical } \\
\text { Activity }\end{array}$ & & \\
\hline 5 or more days per week & 156 & 31.8 \\
\hline Less than 5 days per week & 334 & 68.2 \\
\hline Occupational Status & & \\
\hline Professional & 203 & 41.4 \\
\hline White collar & 434 & 49.8 \\
\hline Blue collar & & 8.8 \\
\hline Hours Spent Working at Job & & \\
\hline & & \\
\hline
\end{tabular}




\begin{tabular}{|l|l|l|}
\hline 30 or more hours per week & 321 & 65.5 \\
\hline Less than 30 hours per week & 169 & 34.5 \\
\hline Hours Spent Providing Unpaid Care & & \\
\hline 1 hour or more per week & 49 & 10.0 \\
\hline No caregiving hours & 441 & 90.0 \\
\hline
\end{tabular}


Table 2: Logistic Regression Results of the Association Between Occupation, Hours Worked, Hours Spent Caregiving and Physical Activity Among Women Aged 18 to 64 (n=490).

\begin{tabular}{|c|c|c|c|c|c|c|c|c|}
\hline & \multicolumn{2}{|c|}{ Model 1} & \multicolumn{2}{|c|}{ Model 2} & \multicolumn{2}{|c|}{ Model 3} & \multicolumn{2}{|c|}{ Model 4} \\
\hline & OR & $95 \%$ CI & OR & $95 \%$ CI & OR & $95 \%$ CI & OR & 95\% CI \\
\hline \multicolumn{9}{|l|}{ Occ. Status } \\
\hline Professional & 1.00 & & 1.00 & & 1.00 & & 1.00 & \\
\hline White collar & 0.93 & $(0.62-1.39)$ & 0.98 & $(0.65-1.47)$ & 0.95 & $(0.64-1.43)$ & 1.01 & $(0.67-1.54)$ \\
\hline Blue collar & $2.43^{*}$ & $(1.01-5.84)$ & $2.56^{*}$ & $1.06-6.18)$ & $2.44 *$ & $(1.02-5.86)$ & 2.25 & $(0.92-5.50)$ \\
\hline \multicolumn{9}{|l|}{ Hrs at job } \\
\hline $\begin{array}{l}30 \text { or more } \\
\mathrm{hr} / \mathrm{wk}\end{array}$ & & & 1.00 & & & & 1.00 & \\
\hline $\begin{array}{l}\text { Less than } 30 \\
\mathrm{hr} / \mathrm{wk}\end{array}$ & & & 0.74 & $(0.49-1.11)$ & & & 0.70 & $(0.46-1.06)$ \\
\hline \multicolumn{9}{|l|}{$\begin{array}{l}\text { Hrs on unpaid } \\
\text { care }\end{array}$} \\
\hline $\begin{array}{l}1 \mathrm{hr} \text { or } \\
\text { more/wk }\end{array}$ & & & & & 1.00 & & 1.00 & \\
\hline $0 \mathrm{hrs} / \mathrm{wk}$ & & & & & 1.49 & $(0.80-2.79)$ & 1.50 & $(0.79-2.83)$ \\
\hline $\begin{array}{l}\text { Dependents } \\
(<\mathbf{1 8 y}) \text { in the } \\
\text { home }\end{array}$ & & & & & & & & \\
\hline & & & & & & & & \\
\hline
\end{tabular}




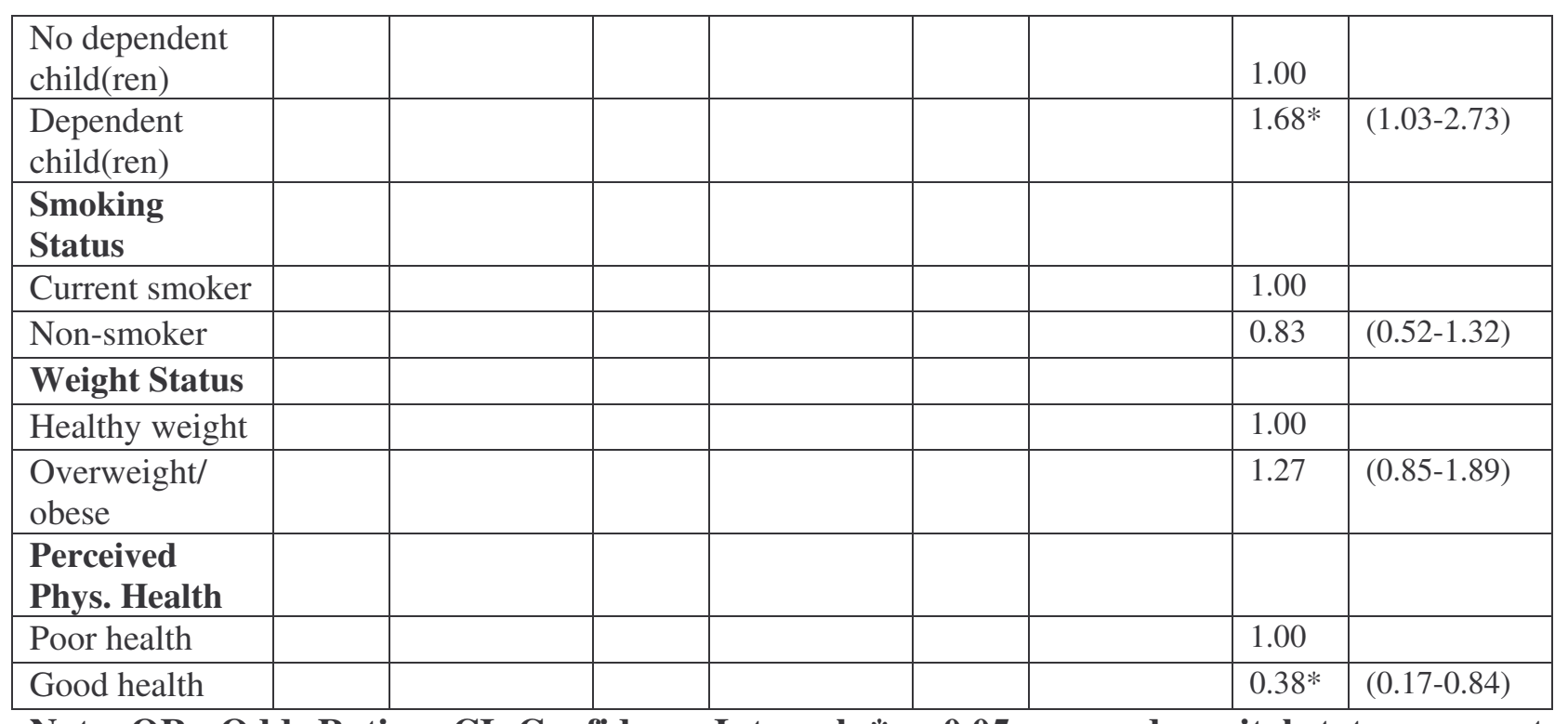

Note: $\mathrm{OR}=$ Odds Ration: $\mathrm{CI}=$ Confidence Interval: $* \mathbf{p}<\mathbf{0 . 0 5}$ : age and marital status are controlled in all models. 